\title{
Anti-inflammatory effects of luteolin on experimental autoimmune thyroiditis in mice
}

\author{
NAN XIA ${ }^{1,2^{*}}$, GANG CHEN $^{3 *}$, MIN LIU $^{1}$, XIAOZHEN YE $^{2}$, YAHUI PAN $^{1}$, \\ JIUYU GE ${ }^{4}$, YANTING MAO ${ }^{1}$, HONGWEI WANG $^{1}$, JIAN WANG $^{2}$ and SIJING XIE ${ }^{1,4}$ \\ ${ }^{1}$ Jiangsu Key Laboratory of Molecular Medicine, School of Medicine, Nanjing University, Nanjing, \\ Jiangsu 210093; ${ }^{2}$ Department of Endocrinology, Jingling Hospital, School of Medicine, Nanjing University, Nanjing, \\ Jiangsu 210002; ${ }^{3}$ Department of Esthetic Plastic Surgery, The First Affiliated Hospital, Nanjing University of \\ Traditional Chinese Medicine, Nanjing, Jiangsu 210029; ${ }^{4}$ Department of Endodontics, Nanjing Stomatology \\ Hospital, School of Medicine, Nanjing University, Nanjing, Jiangsu 210008, P.R. China
}

Received October 26, 2015; Accepted September 22, 2016

DOI: $10.3892 /$ etm.2016.3854

\begin{abstract}
Hashimoto's thyroiditis (HT) is the most common organ-specific autoimmune disease and is believed to be a predominately $\mathrm{T}$ cell-mediated autoimmunity. Signal transducer and activator of transcription (STAT) 3 is a crucial transcription factor of $\mathrm{T}$ cell-mediated immunity, with key roles in the proliferation and migration of $\mathrm{T}$ helper (Th) cells, differentiation of Th cells into Th17 cells, and the balance between Treg cells and Th17 cells. Flavonoid luteolin has been shown to markedly inhibit Tyr705 activation/phosphorylation of STAT3 and exert anti-inflammatory effects in multiple sclerosis. In the present study, the effect of luteolin on experimental autoimmune thyroiditis (EAT) was analyzed in C57BL/6 mice. Hematoxylin and eosin examination showed that luteolin attenuated lymphocytic infiltration and follicle destruction in thyroid glands. Immunohistochemistry results demonstrated that luteolin significantly reduced the phosphorylation of STAT3 within the thyroid. An in vitro study was carried out in a RAW264.7 macrophage cell line. Western blot findings demonstrated that luteolin significantly inhibited interferon- $\gamma$-induced increases in cyclooxygenase 2, phosphorylated STAT1 and phosphorylated STAT3 expression levels and the secretion
\end{abstract}

Correspondence to: Dr Sijing Xie, Department of Endodontics, Nanjing Stomatology Hospital, School of Medicine, Nanjing University, 321 Zhongshan Road, Nanjing, Jiangsu 210008, P.R. China E-mail: xsj801119@163.com

Professor Jian Wang, Department of Endocrinology, Jingling Hospital, School of Medicine, Nanjing University, 305 Zhongshan East Road, Nanjing, Jiangsu 210002, P.R. China

E-mail: wangjndcrn@aliyun.com

*Contributed equally

Key words: luteolin, Hashimoto's thyroiditis, signal transducer and activator of transcription 3 , autoimmune diseases of the proinflammatory cytokine tumor necrosis factor- $\alpha$ in supernatants. The present findings indicated that luteolin may exert potent anti-inflammatory effects on murine EAT, which may provide a novel therapeutic medication strategy for the early intervention of HT.

\section{Introduction}

Hashimoto's thyroiditis (HT) was first discovered by Hakaru Hashimoto in 1912. It is now recognized as the most common autoimmune disease (1), and the most frequent cause of hypothyroidism (2). Diagnosis of HT is based on thyroid dysfunction, an enlarged thyroid gland with a diffusely hypoechogenic pattern by ultrasound examination, and detection of serum thyroid peroxidase (TPO) and thyroglobulin (TG) antibodies, of which TPO is more important (3). It is now believed that HT is a predominately $\mathrm{T}$ cell-mediated autoimmunity $(4,5)$. TPO-specific $\mathrm{T}$ cells alone are able to induce thyroid destruction, leading to hypothyroidism (6). It has been reported that $\mathrm{CD} 4^{+} \mathrm{CD} 25^{+} \mathrm{T}$ cell depletion increases the incidence of autoimmune thyroid disease (AITD) (7), indicating that the imbalance between effector $\mathrm{T}$ cells and regulatory $\mathrm{T}$ cells (Treg) may be a key factor in the pathogenesis of AITD. Clinical statistics have also demonstrated that intrathyroidal Treg cells were decreased in patients with AITD, contributing to the incomplete regulation of autoreactive $\mathrm{T}$ cells and immune tolerance in $\operatorname{AITD}(8,9)$. In addition, T helper 17 (Th17) cells is also one subset of CD4+ T cells that may be associated with the pathogenesis of AITD $(10,11)$. A newly identified subset of $\mathrm{T}$ cells, known as follicular helper $\mathrm{T}$ ( $\mathrm{Tfh}$ ) cells, has also been reported to have an important role in autoimmune disease (12). As a crucial transcription factor for the pathogenesis of autoimmunity, signal transducer and activator of transcription (STAT)3 has a key role in Th17 differentiation (13). Pathogenic Th17 responses in mice are restrained by Tregs and this function is dependent on the role of STAT3 (14). Balance and homeostasis between these two subsets are modulated by STAT3 (15), indicating the essential role of STAT3 in the immunological mechanisms of autoimmune diseases, including AITD. In addition to STAT3, STAT1 
also has a critical role in the signal transduction pathway of interferon-gamma (IFN- $\gamma$ ) and may be a novel target for anti-inflammatory treatment.

Flavonoids, a plant-derived food, are considered to exert anti-inflammatory effects (16). As one of the most common flavonoids, luteolin is present in numerous edible plants and plants used in traditional Chinese medicine. Luteolin has been shown to possess anti-inflammatory activity both in vitro and in vivo (17-20). Previous studies have demonstrated that Tyr705 activation/phosphorylation of STAT3 is markedly inhibited by luteolin $(21,22)$, and luteolin has also been shown to inhibit the phosphorylation of STAT1 (23). In addition, as an anti-inflammatory medication, luteolin has been proven to be effective against other autoimmune diseases, including multiple sclerosis $(24,25)$ and experimental autoimmune encephalomyelitis (26). Therefore, the present study focused on the effects of luteolin on experimental autoimmune thyroiditis (EAT) and the possible mechanisms associated with STAT1 and STAT3 were discussed.

\section{Materials and methods}

Animals. A total of 30 female 8-week-old C57BL/6 mice weighing 20.35 $\pm 0.86 \mathrm{mg}$ were purchased from Model Animal Research Center of Nanjing University (Nanjing, China). Prior to the study, the mice were housed in a clean-grade animal breeding center with an indoor temperature of $20-24^{\circ} \mathrm{C}$ and humidity of $50-70 \%$, under alternate dark/light cycles. Tap water and laboratory feed were available ad libitum. All procedures were performed in accordance with the guidelines outlined by the Animal Research Ethics Committee of Jinling Hospital (Nanjing, China).

Chemicals and reagents. Luteolin was purchased from the National Institute for the Control of Pharmaceutical and Biological Products (Jilin, China). Luteolin $(20 \mathrm{mg} / \mathrm{ml})$ was dissolved in DMSO and stored at $-20^{\circ} \mathrm{C}$. Fetal bovine serum (FBS), Dulbecco's modified Eagle's medium (DMEM), penicillin and streptomycin were obtained from Invitrogen (Thermo Fisher Scientific, Inc., Waltham, MA, USA). Mouse T4 and TNF- $\alpha$ enzyme-linked immunosorbent assay (ELISA) kits were purchased from ExCell (Shanghai, China). Antibodies used in western blot and immunohistochemistry were as follows: Rabbit monoclonal phospho-STAT3 antibodies (Tyr705; \#9145), rabbit monoclonal phospho-STAT1 antibodies (Tyr701; \#9167), rabbit monoclonal STAT3 antibodies (\#9139), rabbit monoclonal STAT1 antibodies (\#14994) and rabbit COX2 antibodies (\#12282), and were all purchased from Cell Signaling Technology, Inc. (Beverly, MA, USA). Rabbit GAPDH antibodies (\#BS60630) and horseradish peroxidase (HRP)-conjugated goat anti-rabbit antibodies (\#BS10043) were purchased from Bioworld Technology, Inc. (Nanjing, China).

\section{In vivo study}

Establishment of an EAT model and treatment with luteolin. Mice were divided into four groups: Luteolin $(n=10)$, dexamethasone (Dex; $n=5$; positive control), $\mathrm{Tg}(\mathrm{n}=10)$, and control $(\mathrm{n}=5)$. For the induction of autoimmune thyroiditis, $100 \mu \mathrm{g}$ porcine Tg (pTg; Sigma-Aldrich; Merck Millipore, Darmstadt, Germany) was emulsified in $100 \mu 1$ Freund's complete adjuvant
(CFA; Sigma-Aldrich; Merck Millipore) and was subcutaneously injected into each mouse (except the control) on day 0 . A second subcutaneous injection was administered on day 14 using the same amount of pTg in incomplete Freund's adjuvant (IFA; Sigma-Aldrich; Merck Millipore). Following the second immunization, Luteolin and Dex-treated mice were given daily intraperitoneal injections of luteolin $(10 \mathrm{mg} / \mathrm{kg} /$ day $)$ and dexamethasone $(5 \mathrm{mg} / \mathrm{kg} /$ day; both Sigma-Aldrich; Merck Millipore), respectively, whereas TG mice were administered PBS instead. After 7 days of treatment, all mice were sacrificed by cervical dislocation following pentobarbital anesthesia (50 mg/kg, i.p.). Blood samples and thyroid tissues were obtained. Sera were stored at $-80^{\circ} \mathrm{C}$. Thyroid tissues were fixed in $4 \%$ paraformaldehyde solution, sectioned, and hematoxylin and eosin (H\&E) staining and immunohistochemistry (IHC) were performed for histopathological examination. Mononuclear cell infiltration index was scored as follows: 0, no infiltration; 1, interstitial accumulation of cells between two or three follicles; 2 , one or two foci of cells at least the size of one follicle; 3 , extensive infiltration, $10-40 \%$ of total area; 4 , extensive infiltration, $40-80 \%$ of total area; and 5, extensive infiltration $>80 \%$ of total area.

Detection of serum T4 and antibodies against pTg. Serum T4 was assayed using ELISA according to manufacturer's instructions. Antibodies against pTg were detected by ELISA. Briefly, flat-bottomed 96-well plates (Costar 3590; Corning, Inc., Corning NY, USA) were coated overnight at $4^{\circ} \mathrm{C}$ with $100 \mu 1$ pTg (\#T1126; Sigma-Aldrich; Merck Millipore) diluted to $100 \mu \mathrm{g} / \mathrm{ml}$ in PBS, and then washed twice with PBS with $0.05 \%$ Tween 20 (PBST). Free protein binding sites were blocked by adding $1 \%$ bovine serum albumin (BSA) for $2 \mathrm{~h}$ at $37^{\circ} \mathrm{C}$. Following washing with PBST, the sera from individual mice were diluted 1:1,600 in PBS with 1\% BSA and incubated overnight at $4^{\circ} \mathrm{C}$. Following extensive washing of the plates, HRP-conjugated goat anti-mouse IgG (1030-05; Southern Biotech, Birmingham, AL, USA), diluted 1:5,000 in PBS with $1 \% \mathrm{BSA}$, was added and the plates were incubated for $1 \mathrm{~h}$ at $37^{\circ} \mathrm{C}$ and subsequently washed. The substrate, $50 \mu \mathrm{l} /$ well tetramethylbenzidine, was added for $20 \mathrm{~min}$ and the reaction was terminated with $50 \mu \mathrm{l} /$ well $2 \mathrm{NH}_{2} \mathrm{SO}_{4}$, after which the optical density was measured at $450 \mathrm{~nm}$.

\section{In vitro study}

Cell culture and treatment. RAW264.7 mouse macrophage cell line was obtained from the Type Culture Collection of the Chinese Academy of Sciences (Shanghai, China). Cells were maintained in DMEM supplemented with $10 \%$ FBS and antibiotics (100 U/ml penicillin and $100 \mathrm{U} / \mathrm{ml}$ streptomycin). In brief, cells were grown in 6-well plates and stimulated by human IFN- $\gamma(10 \mathrm{ng} / \mathrm{ml})$ overnight. Cells were treated with luteolin $(20 \mu \mathrm{mol} / \mathrm{l})$ for $6 \mathrm{~h}$ the next day.

Western blot analysis. Western blotting was performed to detect the expression of COX2, an anti-inflammatory marker, and STAT1 and STAT3 transcription factors, which are downstream of the interleukin (IL)-6 signaling pathway. Cells were washed with PBS, harvested and lysed using radioimmunoprecipitation assay buffer. Protein concentrations were determined using a bicinchoninic protein kit according to the 
manufacturer's instructions. Protein $(50 \mu \mathrm{g})$ of each sample was resolved using 10\% SDS-PAGE, then transferred to a PVDF membrane. The membrane was blocked with 5\% BSA for $2 \mathrm{~h}$ at room temperature, then washed with TBST $(1: 1,000)$ three times. Phospho-STAT3 (Tyr705; \#9145), phospho-STAT1 (Tyr701; \#9167), total STAT3 (\#9139), total STAT1 (\#14994), COX2 (\#12282) and GAPDH antibodies (\#BS60630) were used at a dilution of 1:1,000 and incubated at $4^{\circ} \mathrm{C}$ overnight, followed by HRP-conjugated goat anti-rabbit antibodies (\#BS10043) at a dilution of 1:20,000 for $80 \mathrm{~min}$ at room temperature. Detection of HRP-conjugated antibodies was performed using an ECL Plus Blotting Reagent and a Quality One documentation system (Bio-Rad Laboratories, Inc., Hercules, CA, USA).

Cytokine assay. TNF- $\alpha$ concentrations were measured in the supernatants of cultured RAW264.7 cells using a sandwich ELISA kit (\#EM008-48; ExCell, Shanghai, China) according to the manufacturer's instructions.

Statistical analysis. Statistical analysis was performed using GraphPad Prism software, version 6.0 (GraphPad Software, Inc., La Jolla, CA, USA). Data was analyzed using the t-test and one-way analysis of variance. $\mathrm{P}<0.05$ was considered to indicate a statistically significant difference.

\section{Results}

Luteolin inhibits lymphocytic infiltration in thyroids of EAT mice. Anatomical observation demonstrated that 4/10 mice manifested with a goiter (Fig. 1A), indicating the occurrence of EAT. H\&E examination of thyroid glands demonstrated that $43 \pm 5.7 \%$ TG mice exhibited infiltration of immune cells between follicles, whereas the incidences of Luteolin and Dex-treated mice are $23 \pm 5.7$ and $17 \pm 11.5 \%$, respectively. The infiltration index of the thyroid sections also indicated significantly decreased infiltration of lymphocytes in the luteolin and Dex-treated mice, compared with the TG-treated mice $(\mathrm{P}<0.05$, Fig. 1B and C).

Luteolin reduces plasma T4 levels, while increases plasma anti-pTG levels. T4 concentrations and anti-pTG antibodies were evaluated via ELISA assays. The results demonstrated that all three groups with EAT (Dex, Luteolin and TG) exhibited increased anti-TG antibodies compared with control mice, and luteolin and Dex treatment both significantly increased antibody levels compared with the TG group ( $\mathrm{P}<0.05$; Fig. $2 \mathrm{~A})$. Serum T4 concentrations in TG mice were mildly elevated, compared with the other groups, but the difference was not significant ( $\mathrm{P}>0.05$; Fig. 2B).

Luteolin inhibits STAT3 phosphorylation in thyroid glands. The effect of luteolin on the phosphorylation of STAT3 (Y705) in thyroid sections was evaluated by IHC. Phosphorylated STAT3 expression was significantly increased in TG mice compared with the control $(\mathrm{P}<0.05)$, whereas luteolin and Dex treatment markedly inhibited this alteration (Fig. 2C and D).

Luteolin inhibits the expression of COX2 and phosphorylation of STAT1 and STAT3. Western blot analysis of RAW264.7 macrophage cell line demonstrated that luteolin markedly

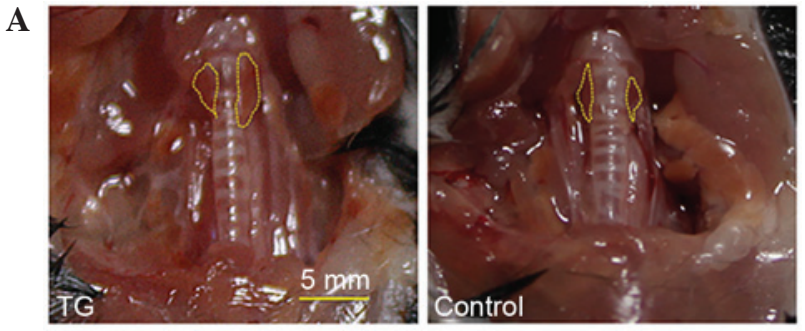

B

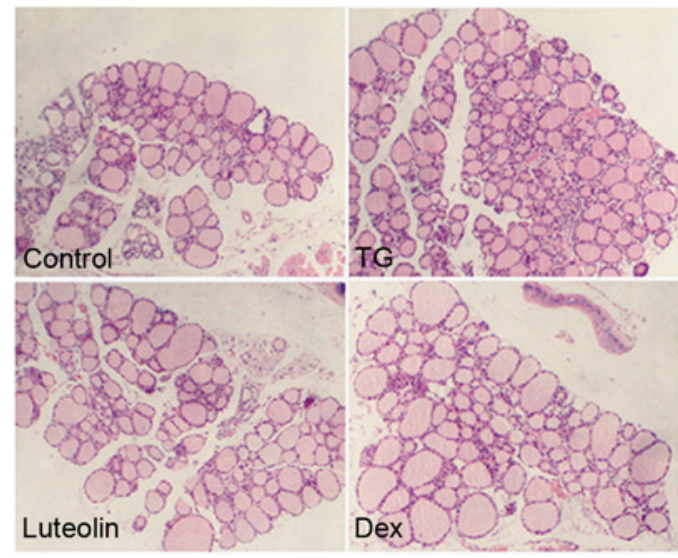

C

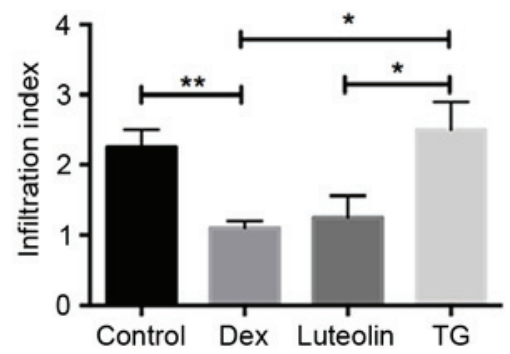

Figure 1. Luteolin significantly inhibited the infiltration of lymphocytes caused by autoimmune thyroiditis. (A) 4/10 mice exhibited enlargement of the thyroid glands. (B) Hematoxylin and eosin staining were performed in all mice; $40 \%$ of the section from TG-treated mice demonstrated a large amount of lymphocytic infiltration between the follicles compared with the control (magnification, $\mathrm{x} 40$ ). Luteolin and Dex mice-treated exhibited markedly decreased levels of infiltration of immune cells. (C) Infiltration index of monocytes in the thyroid sections in each group, ${ }^{*} \mathrm{P}<0.05 ;{ }^{* *} \mathrm{P}<0.01$. TG thyroglobulin; Dex, dexamethasone.

inhibited the increased expression of COX2, phosphorylated (p)-STAT1 (Y701) and p-STAT3 (Y705) induced by IFN- $\gamma$ treatment, whereas total STAT1 and STAT3 remained unchanged. These findings demonstrated the anti-inflammatory effect of luteolin by inhibiting the STAT1 and STAT3 signaling pathway in vitro (Fig. 3A).

Luteolin reduces TNF- $\alpha$ secretion in the RAW264.7 cell line. TNF- $\alpha$ concentrations were measured in the supernatants of RAW264.7 cells using ELISA kits. TNF- $\alpha$ concentration levels were significantly increased when treated with IFN- $\gamma$, whereas they were markedly decreased after treatment with luteolin $(\mathrm{P}<0.05$; Fig. 3B).

\section{Discussion}

STAT3 has an important role in T cell-mediated immunity, including the proliferation (27) and migration (28) of T cells, 

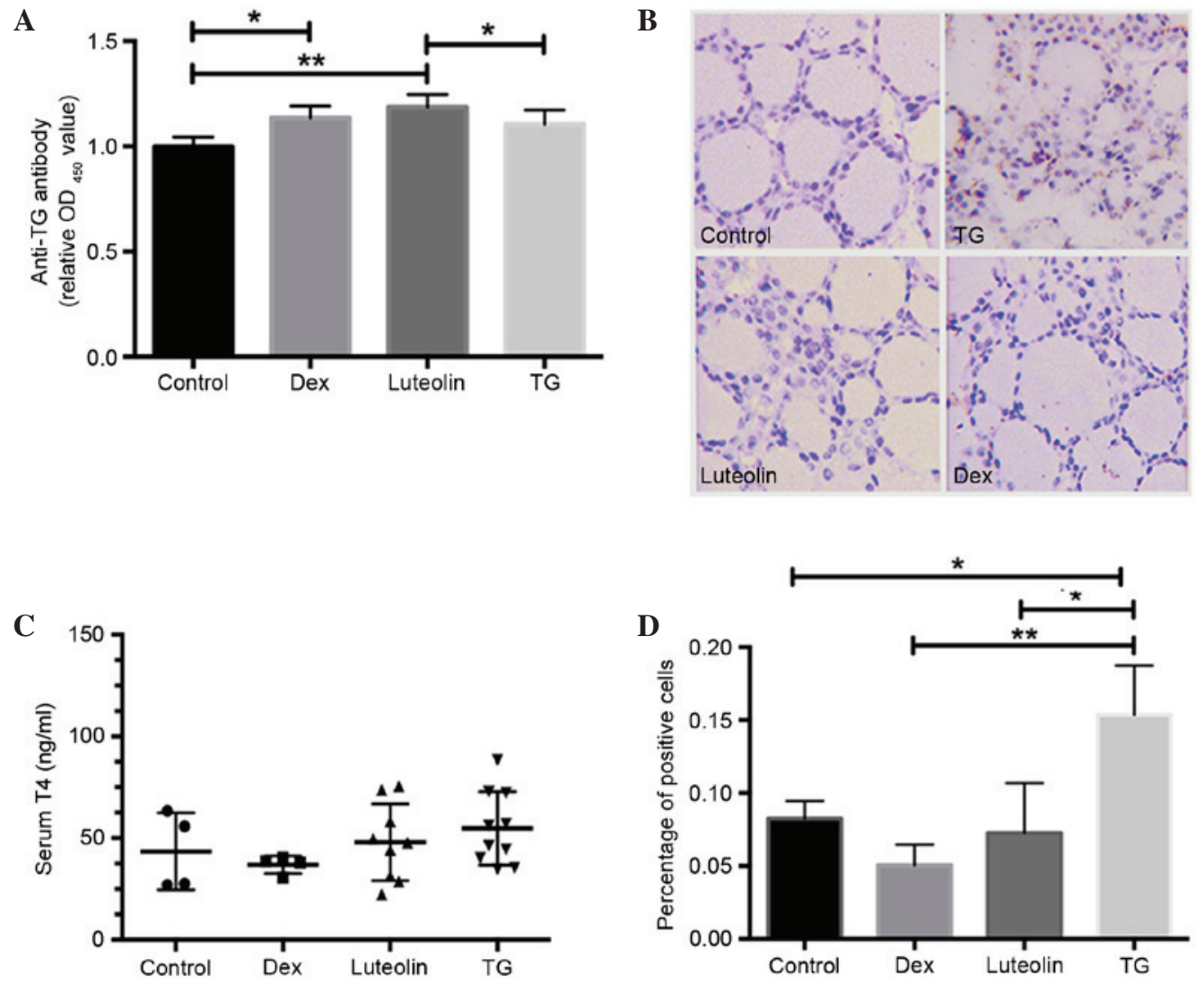

Figure 2. Luteolin inhibited the phosphorylation of STAT3 in thyroid glands. (A) Serum TG antibodies were detected by ELISA. All three groups with EAT (Dex, Luteolin and TG) exhibited increased anti-TG antibody levels compared with the control. (B) Serum T4 concentrations were detected by ELISA. TG-treated mice demonstrated mildly elevated T4 levels compared with the other groups, without significance $(\mathrm{P}>0.05)$. (C) Thyroid sections of TG mice stained positive for p-STAT3 (Y705) during immunohistochemical analysis (magnification, x400), whereas the other groups stained negative. (D) Quantification analysis based on the percentage of positively stained cells in one visual field. Four visual fields were selected randomly in every section. All values are expressed as mean \pm standard deviation. ${ }^{*} \mathrm{P}<0.05 ;{ }^{* * *} \mathrm{P}<0.01$. TG thyroglobulin; Dex, dexamethasone.

differentiation into Th17 cells (29), and balance between Treg cells and Th17 cells $(30,31)$. Moreover, STAT3 and its downstream SOCS3 gene polymorphism are associated with AITD susceptibility and IL-6 secretion (32-34). Cytokines, such as IL-6, are important in the pathogenesis of AITD due to their functions in recruiting inflammatory cells in the thyroid, upregulating some inflammatory molecules and interfering in the production of thyroid hormones (35). It has been demonstrated that IL-6-STAT3 signaling has a crucial role in dendritic cell differentiation during $\mathrm{T}$ cell-mediated immune responses in vivo (36). Thyroid follicular epithelial cells are able to synthesize and secrete large quantities of IL-6 (37), which further promotes the development of autoimmune responses. Therefore, it is theoretically reasonable to target IL-6/STAT3 to intervene in the early stage of autoimmune thyroiditis in order to explore novel therapeutic strategies for HT. Previous studies have shown that luteolin has potent anti-inflammatory effects in vitro and in vivo $(38,39)$ and the mechanisms involved include the activation of NF- $\mathrm{KB}$, which leads to the expression of IL-6 and COX-2 $(18,40)$. Activator protein-1 (AP-1) is also an important transcription factor associated with immune responses. Expression of IL- 6 is induced by AP- 1 and NF-KB (41). Jang et al (41) found that luteolin was able to reduce LPS-induced IL-6 expression by inhibiting JNK and AP-1 pathways both in vitro and in vivo, and the mice treated with luteolin exhibited decreased plasma and hippocampal IL-6 levels.
HT, which is also known as chronic lymphocytic thyroiditis, is the most common autoimmune disease. There is usually a long latency period before hypothyroidism occurs (42). Therefore, early intervention may theoretically prevent the development of the disease and maintain the normal structure and function of the thyroid glands. Thus, the present study aimed to explore the anti-inflammatory effects of luteolin on autoimmune thyroiditis and the mechanisms involved. A classical C57BL/6 mouse model of EAT was established. As a result, 4/10 mice exhibited goiter symptoms and infiltration of mononuclear cells into the thyroid glands. C57BL/6 mice are known to have a relative low incidence of EAT (43), which is consistent with the present findings. The effects of luteolin on EAT were subsequently evaluated. Mice treated with luteolin demonstrated significantly reduced infiltration of lymphocytes compared with TG mice. As an intracellular inhibitor of IL-6/STAT1 and STAT3 signaling pathway, luteolin significantly inhibited the phosphorylation of STAT1 and STAT3 in thyroid glands, as identified by H\&E examination.

Anti-Tg antibodies were also elevated in the three EAT groups, as compared with the control; however, the treatment of luteolin and Dex appeared to further increase the antibodies. Although the mechanisms remain unknown, clinical data has shown that thyroid antibodies are elevated shortly after ${ }^{131}$ iodine treatment for hyperthyroidism (44). The mechanisms involved require further investigation. In addition, serum T4 
A
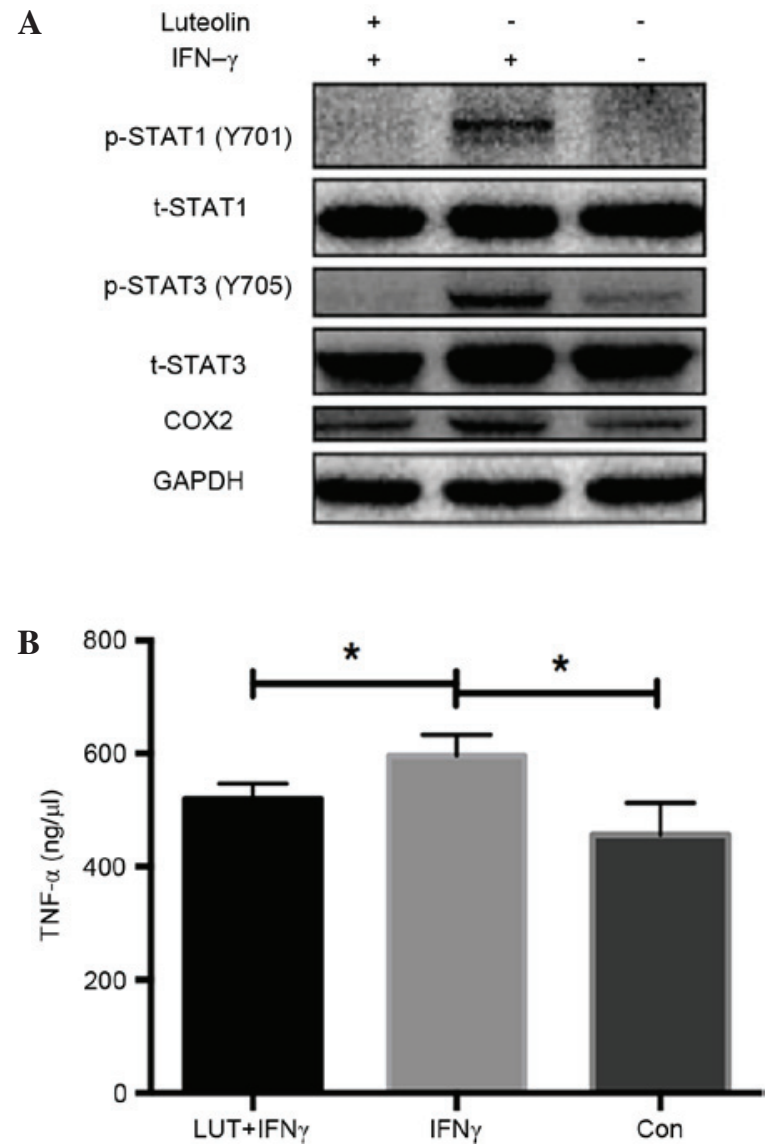

Figure 3. Luteolin inhibits the expression of COX2 and the phosphorylation of STAT1 and STAT3 and reduced TNF- $\alpha$ secretion in the RAW264.7 cell line. (A) RAW264.7 macrophages were stimulated by human IFN- $\gamma(10 \mathrm{ng} / \mathrm{ml})$ overnight, and treated with luteolin $(20 \mu \mathrm{mol} / \mathrm{l})$ for $6 \mathrm{~h}$ the following day. Western blot results demonstrated that luteolin exerts an anti-inflammatory effect by inhibiting the increased expression of COX2, p-STAT1 (Y701) and p-STAT3 (Y705) induced by IFN- $\gamma$ treatment, whereas total STAT1 and total STAT3 remain unchanged. (B) Concentrations of TNF- $\alpha$ were measured in the supernatants of cultured RAW264.7 cells using ELISA kits. TNF- $\alpha$ levels were significantly increased when treated with IFN- $\gamma$, whereas they were markedly decreased after treatment with luteolin. ${ }^{*} \mathrm{P}<0.05$. IFN, interferon; p, phosphorylated; STAT, signal transducer and activator of transcription; COX, cyclooxygenase; TNF, tumor necrosis factor.

levels were slightly elevated in TG mice, which may be due to the thyroid damage caused by thyroiditis. Luteolin appears to reduce the release of T4 into the blood; however, no statistical significance was detected.

Western blot analysis of RAW264.7 cells demonstrated that luteolin exerted anti-inflammatory effects by significantly inhibiting the IFN- $\gamma$-induced increase of COX 2 and p-STAT1 (Y701) and p-STAT3 (Y705) expression, whereas total STAT1 and STAT3 remained unchanged. COX-2 is an inducible enzyme (45), which is highly expressed in cells involved in the inflammatory response including monocytes/macrophages and mast cells. Cytokine TNF- $\alpha$ detection in supernatants also demonstrated that luteolin exhibited anti-inflammatory effects by significantly reducing TNF- $\alpha$ secretion in vitro.

Additional experiments are required to elucidate the anti-inflammatory mechanisms of luteolin, which may include the IL-6/ STAT1 and STAT3 pathways discussed in the present study or other pathways. Even if the immunosuppressive effects are mediated solely through the IL-6 pathway, addi- tional proteins or molecules involved in the process remain to be discovered.

In conclusion, treatment with luteolin exhibited a significant immunosuppressive effect by attenuating lymphocytic infiltration and the destruction of the thyroid epithelia in thyroid glands, which is likely to have occurred via the inhibition of IL-6/STAT1 and STAT3 signaling pathway in the glands. The present study provides evidence for a promising novel therapeutic strategy for the early intervention of autoimmune thyroiditis. Further investigation is required to fully elucidate the mechanisms involved.

\section{References}

1. McLeod DS and Cooper DS: The incidence and prevalence of thyroid autoimmunity. Endocrine 42: 252-265, 2012.

2. Vaidya B and Pearce SH: Management of hypothyroidism in adults. BMJ 337: a801, 2008.

3. Caturegli P, De Remigis A and Rose NR: Hashimoto thyroiditis: Clinical and diagnostic criteria. Autoimmun Rev 13: 391-397, 2014.

4. Chistiakov DA: Immunogenetics of Hashimoto's thyroiditis. J Autoimmune Dis 2: 1, 2005.

5. McLachlan SM and Rapoport B: Autoimmune hypothyroidism: T cells caught in the act. Nat Med 10: 895-896, 2004.

6. Quaratino S, Badami E, Pang YY, Bartok I, Dyson J, Kioussis D, Londei M and Maiuri L: Degenerate self-reactive human T-cell receptor causes spontaneous autoimmune disease in mice. Nat Med 10: 920-926, 2004.

7. Saitoh O and Nagayama Y: Regulation of Graves' hyperthyroidism with naturally occurring CD4+ CD25+ regulatory T cells in a mouse model. Endocrinology 147: 2417-2422, 2006.

8. Nakano A, Watanabe M, Iida T, Kuroda S, Matsuzuka F, Miyauchi A and Iwatani Y. Apoptosis-induced decrease of intrathyroidal CD4+ CD25+ regulatory T cells in autoimmune thyroid diseases. Thyroid 17: 25-31, 2007.

9. Wang SH and Baker JR: The role of apoptosis in thyroid autoimmunity. Thyroid 17: 975-979, 2007.

10. Shi Y, Wang H, Su Z, Chen J, Xue Y, Wang S, Xue Y, He Z, Yang H, Zhou C, et al: Differentiation imbalance of Th1/Th17 in peripheral blood mononuclear cells might contribute to pathogenesis of Hashimoto's thyroiditis. Scand J Immunol 72: 250-255, 2010.

11. Li D, Cai W, Gu R, Zhang Y, Zhang H, Tang K, Xu P, Katirai F, Shi W, Wang L, et al: Th17 cell plays a role in the pathogenesis of Hashimoto's thyroiditis in patients. Clin Immunol 149: 411-420, 2013.

12. Zhu C, Ma J, Liu Y, Tong J, Tian J, Chen J, Tang X, Xu H, Lu L and Wang S: Increased frequency of follicular helper $\mathrm{T}$ cells in patients with autoimmune thyroid disease. J Clin Endocrinol Metab 97: 943-950, 2012.

13. Harris TJ, Grosso JF, Yen HR, Xin H, Kortylewski M, Albesiano E, Hipkiss EL, Getnet D, Goldberg MV, Maris CH, et al: Cutting edge: An in vivo requirement for STAT3 signaling in TH17 development and TH17-dependent autoimmunity. J Immunol 179: 4313-4317, 2007.

14. Chaudhry A, Rudra D, Treuting P, Samstein RM, Liang Y, Kas A and Rudensky AY: CD4+ regulatory T cells control TH17 responses in a Stat3-dependent manner. Science 326: 986-991, 2009.

15. Durant L, Watford WT, Ramos HL, Laurence A, Vahedi G, Wei L, Takahashi H, Sun HW, Kanno Y, Powrie F and O'Shea JJ: Diverse targets of the transcription factor STAT3 contribute to $\mathrm{T}$ cell pathogenicity and homeostasis. Immunity 32: 605-615, 2010.

16. Kim HP, Son KH, Chang HW and Kang SS: Anti-inflammatory plant flavonoids and cellular action mechanisms. J Pharmacol Sci 96: 229-245, 2004.

17. López-Lázaro M: Distribution and biological activities of the flavonoid luteolin. Mini Rev Med Chem 9: 31-59, 2009.

18. Xagorari A, Papapetropoulos A, Mauromatis A, Economou M, Fotsis $\mathrm{T}$ and Roussos C: Luteolin inhibits an endotoxin-stimulated phosphorylation cascade and proinflammatory cytokine production in macrophages. J Pharmacol Exp Ther 296: 181-197, 2001. 
19. Kritas SK, Saggini A, Varvara G, Murmura G, Caraffa A, Antinolfi P, Toniato E, Pantalone A, Neri G, Frydas S, et al: Luteolin inhibits mast cell-mediated allergic inflammation. J Biol Regul Homeost Agents 27: 955-959, 2013.

20. Ziyan L, Yongmei Z, Nan Z, Ning T and Baolin L: Evaluation of the anti-inflammatory activity of luteolin in experimental animal models. Planta Med 73: 221-226, 2007.

21. Selvendiran K, Koga H, Ueno T, Yoshida T, Maeyama M, Torimura T, Yano H, Kojiro M and Sata M: Luteolin promotes degradation in signal transducer and activator of transcription 3 in human hepatoma cells: An implication for the antitumor potential of flavonoids. Cancer Res 66: 4826-4834, 2006.

22. Parker-Athill E, Luo D, Bailey A, Giunta B, Tian J, Shytle RD, Murphy T, Legradi G and Tan J: Flavonoids, a prenatal prophylaxis via targeting JAK2/STAT3 signaling to oppose IL-6/MIA associated autism. J Neuroimmunol 217: 20-27, 2009.

23. Rezai-Zadeh K, Ehrhart J, Bai Y, Sanberg PR, Bickford P, Tan J and Shytle RD: Apigenin and luteolin modulate microglia activation via inhibition of STAT1-induced CD40 expression. J Neuroinflammation 5: 41, 2008.

24. Theoharides TC: Luteolin as a therapeutic option for multiple sclerosis. J Neuroinflammation 6: 29, 2009.

25. Theoharides TC, Kempuraj D and Iliopoulou BP: Mast cells, $\mathrm{T}$ cells and inhibition by luteolin: Implications for the pathogenesis and treatment of multiple sclerosis. Adv Exp Med Biol 601: 423-430, 2007.

26. Beeton C, Pennington MW, Wulff H, Singh S, Nugent D, Crossley G, Khaytin I, Calabresi PA, Chen CY, Gutman GA and Chandy KG: Targeting effector memory T cells with a selective peptide inhibitor of Kv1. 3 channels for therapy of autoimmune diseases. Mol Pharmacol 67: 1369-1381, 2005.

27. Takeda K, Kaisho T, Yoshida N, Takeda J, Kishimoto T and Akira S: Stat3 activation is responsible for IL-6-dependent $\mathrm{T}$ cell proliferation through preventing apoptosis: Generation and characterization of T cell-specific Stat3-deficient mice. J Immunol 161: 4652-4660, 1998.

28. McLoughlin RM, Jenkins BJ, Grail D, Williams AS, Fielding CA Parker CR, Ernst M, Topley N and Jones SA: IL-6 trans-signaling via STAT3 directs T cell infiltration in acute inflammation. Proc Natl Acad Sci USA 102: 9589-9594, 2005.

29. Zhou L, Ivanov II, Spolski R, Min R, Shenderov K, Egawa T, Levy DE, Leonard WJ and Littman DR: IL-6 programs T(H)-17 cell differentiation by promoting sequential engagement of the IL-21 and IL-23 pathways. Nat Immunol 8: 967-974, 2007.

30. Kimura A and Kishimoto T: IL-6: Regulator of Treg/Th17 balance. Eur J Immunol 40: 1830-1835, 2010.

31. Nishihara M, Ogura H, Ueda N, Tsuruoka M, Kitabayashi C, Tsuji $\mathrm{F}$, Aono $\mathrm{H}$, Ishihara $\mathrm{K}$, Huseby $\mathrm{E}$, Betz UA, et al: IL-6-gp130-STAT3 in T cells directs the development of IL-17+ Th with a minimum effect on that of Treg in the steady state. Int Immunol 19: 695-702, 2007.
32. Xiao L, Muhali FS, Cai TT, Song RH, Hu R, Shi XH, Jiang WJ, Li DF, He ST, Xu J and Zhang JA: Association of single-nucleotide polymorphisms in the STAT3 gene with autoimmune thyroid disease in Chinese individuals. Funct Integr Genomics 13: 455-461, 2013.

33. Kotkowska A, Sewerynek E, Domańska D, Pastuszak-Lewandoska D and Brzeziańska E: Single nucleotide polymorphisms in the STAT3 gene influence AITD susceptibility, thyroid autoantibody levels and IL6 And IL17 secretion. Cell Mol Biol Lett 20: 88-101, 2015.

34. Yan R, Yang J, Jiang P, Jin L, Ma J, Huang R, Ma N and Jiang F: Genetic variations in the SOCS3 gene in patients with Graves' ophthalmopathy. J Clin Pathol 68: 448-452, 2015.

35. Ajjan R and Weetman A: Cytokines in thyroid autoimmunity. Autoimmunity 36: 351-359, 2003.

36. Park SJ, Nakagawa T, Kitamura H, Atsumi T, Kamon H, Sawa S, Kamimura D, Ueda N, Iwakura Y, Ishihara K, et al: IL-6 regulates in vivo dendritic cell differentiation through STAT3 activation. J Immunol 173: 3844-3854, 2004.

37. Weetman A, Bright-Thomas R and Freeman M: Regulation of interleukin- 6 release by human thyrocytes. J Endocrinol 127: 357-361, 1990.

38. Kotanidou A, Xagorari A, Bagli E, Kitsanta P, Fotsis T, Papapetropoulos A and Roussos C: Luteolin reduces lipopolysaccharide-induced lethal toxicity and expression of proinflammatory molecules in mice. Am J Respir Crit Care Med 165: 818-823, 2002.

39. Chen CY, Peng WH, Tsai KD and Hsu SL: Luteolin suppresses inflammation-associated gene expression by blocking NF-kappaB and AP-1 activation pathway in mouse alveolar macrophages. Life Sci 81: 1602-1614, 2007.

40. Chen CC, Chow MP, Huang WC, Lin YC and Chang YJ: Flavonoids inhibit tumor necrosis factor-alpha-induced up-regulation of intercellular adhesion molecule-1 (ICAM-1) in respiratory epithelial cells through activator protein-1 and nuclear factor-kappaB: Structure-activity relationships. Mol Pharmacol 66: 683-693, 2004.

41. Jang S, Kelley KW and Johnson RW: Luteolin reduces IL-6 production in microglia by inhibiting JNK phosphorylation and activation of AP-1. Proc Natl Acad Sci USA 105: 7534-7539, 2008

42. Hutfless S, Matos P, Talor MV, Caturegli P and Rose NR: Significance of prediagnostic thyroid antibodies in women with autoimmune thyroid disease. J Clin Endocrinol Metab 96: E1466-E1471, 2011.

43. Maron R and Cohen IR: H-2K mutation controls immune response phenotype of autoimmune thyroiditis. Critical expression of mutant gene product in both thymus and thyroid glands. J Exp Med 152: 1115-1120, 1980.

44. Einhorn J, Fagraeus A and Jonsson J: Thyroid antibodies after 131 I treatment for hyperthyroidism. J Clin Endocrinol Metab 25: 1218-1224, 1965

45. Crofford LJ: COX-1 and COX-2 tissue expression: Implications and predictions. J Rheumatol Suppl 49: 15-19, 1997. 